\title{
The Relevance of Nigeria's Freedom of Information Act (2011) to the Country's Anti-corruption War
}

\author{
Chike Walter Duru \\ Justice For All/British Council, Abuja, Nigeria
}

\begin{abstract}
This essay is centred on Nigeria's Freedom of Information Act, with special interest in its relevance in the country's anti-corruption war. The paper reiterates that the law was passed to enable the public to access certain government information, in order to ensure transparency and accountability. The FOI Act aims to make public records and information more freely available and to protect public records and information, in accordance with the public interest and protection of personal privacy. It enables citizens to hold the government accountable in the event of the misappropriation of public funds or failure to deliver public services. It also seeks to protect serving public officers against any adverse consequences from the unauthorized disclosure of certain kinds of official information, and to establish procedures for the achievement of these purposes. The Act further regulates conflicts between its provisions and those of other legislations. The paper contends that Freedom of Information is a fundamental indicator of economic development and progress, civic engagement and a properly functional democracy in every economy, describing it as a promising start in ensuring good governance and rule of law in Nigeria. The paper stresses the need for vigorous implementation of the FOI Act if the country is to make any significant breakthrough in the enthronement of good governance, transparency and accountability, adding that a strengthened FOI regime will enhance citizens' demand for accountability and check corruption in Nigeria.
\end{abstract}

Keywords: Freedom of Information Act, good governance, anti-corruption, Nigeria

\section{Introduction}

Nigeria's Freedom of Information (FOI) Act was signed into law on May 28, 2011, after the longest legislative debate in the history of Nigeria. The debate lasted for over 12 years. The law was passed to enable the public to access government information, in order to ensure transparency and accountability. The bill was developed by the Freedom of Information Coalition, a network of over 180 civil society organizations in Nigeria, comprising of civil rights, grassroots and community-based Non-Governmental Organizations campaigning for the effective utilization of the Freedom of Information (FOI) Act to ensure accountability and transparency in public institutions in Nigeria.

The FOI Act aims to make public records and information more freely available and to protect public records and information, in accordance with the public interest and protection of personal privacy. It enables citizens to hold the government accountable in the event of the misappropriation of public funds or failure to deliver public services. It also seeks to protect serving public officers against any adverse consequences from the

Chike Walter Duru, Ph.D., Justice For All/British Council. 
unauthorized disclosure of certain kinds of official information. The Act further regulates conflicts between its provisions and those of other legislations (eg) the Criminal Code, Penal Code or Official Secret Act that prescribe criminal penalties for actions connected to the disclosure of Information.

It is against this backdrop that this paper attempts to provide answers to the following questions: In the face of the ravaging and alarming rate of corruption, what role is the FOI Act playing? Going by the culture of secrecy in public service, as promoted by the Official Secrets Act, what relevant changes have the Act effected in Nigeria? What are the challenges militating and confronting the effective use of the Act in entrenching openness in governance? What can be done to ensure vigorous implementation of the Act? In order to address these questions and more, the paper, in addition to the introductory remarks, is presented in eight sections: section two addresses conceptual issues, while section three treats the relationship between the Freedom of Information Act, Democracy and good governance in Nigeria. Sections four and five attempt to address the relevance of the Act and the exemptions therein, respectively; while section six treats its applicability. Section seven addresses the relevance of the FOI Act to the country's anti-corruption war. Section eight concludes the paper, while section nine handles recommendations.

\section{Conceptual Clarifications}

\section{Freedom of Information}

Freedom of Information refers to the right, which the public in any society has to access information held by government officials $\&$ institutions. It is a fundamental human right established under international Law. All citizens of any country and indeed all members of the public are entitled to enjoy this right (Ojo, 2015).

Freedom of Information is the right to access information held by government and public institutions. It steps from the right to freedom of expression which is recognized by Article 19 of the Universal Declaration of Human Rights (1948) and states that freedom of expression encompasses the freedom to seek, receive and impart information and ideas through any media and regardless of Frontiers.

Other international instruments that ratified the right to Freedom of expression include: International Convention on Civil and Political Rights (1966), African Charter on Human Rights and the American Convention on Human Rights (1969), among others.

Freedom of Information is very important, as information is central to human existence. Without communication, the world will remain in darkness. Information is critical in decision making, as the quality of decisions we often make depend on the quality and volume of information at our disposal.

\section{Open Society}

Open society is a concept originally suggested by the French philosopher Henri Bergson but which was developed during the 2nd World War by Austrian-born British philosopher Kerl Popper. Popper saw the open society as standing on a historical continuum reaching from the organic, tribal, or closed society, through the open society marked by a critical attitude to tradition, up to the abstract or depersonalized society lacking all face-to-face transactions (Popper, 1995).

Modern advocates of the open society suggest that society would keep no secrets from itself in the public sense, as all are trusted with the knowledge of all. Political freedoms and human rights are claimed as the foundation of an open society. It is also known as the transparent society with the critical component of a critical frame of mind (Wilson, 2015b). 


\section{Nigeria's Freedom of Information Act 2011}

The drama which characterized the process of passing into law, the Freedom of Information Act, making it perhaps the longest-running bill (1999-2011) in the history of law making in Nigeria will not be forgotten in a hurry. The problem with this great Act is that it has not seriously been tested, which is why there is need for a coordinated strategy to make the law work and realize its potentials (Duru, 2015b).

The Nigerian Freedom of Information (FOI) Act 2011 gives any person the right to ask any public institution for any record, data or information that is held in the institution's custody. Anyone can ask for information regardless of age, gender, disability, citizenship or geographical location. The law gives a legal footing to demand for information from such government bodies except on information that is exempted in the law (Ojo, 2015).

In a paper presentation on the FOI Act and Bureaucratic processes in Nigeria, during a Roundtable on increased compliance of Ministries, Departments and agencies (MDAs), former Director, Freedom of Information Unit of the Federal Ministry of Justice, Mrs. Stella Anukam argued that the Act is designed to entrench accountability and transparency in public institutions:

The main argument of this paper is that FOIA could serve as a framework for the empowerment of Nigerians by institutionalizing transparency and accountability as pillars of governance in Nigeria. The right to relevant public information by the citizenry and the role the full implementation of this right plays on governance and participatory democracy cannot be overemphasized. The denial of access to information and the attendant widespread ignorance in the society does more harm to the society than any harm that could possibly arise from granting access to members of the public. The effective implementation of FOI in Nigeria brings openness, transparency and good governance thereby complementing government's avowed commitment to stamping out corruption in Nigeria. The Nigeria FOI law would assist in stamping out corruption which is described as the bane of the nation. The FOI law facilitates open government because even if some information in a document qualifies for an exemption to FOI law, the rest must be disclosed. Implementing FOIA is the most important way to minimize corruption in the Public Service. According to the Director General of the Bureau of Public Service Reforms (BPSR), Dr. Joe Abah, the country's second most powerful legislation is FOIA, and it is superseded only by the Nigerian Constitution. He said further and I agree absolutely with him that "if we are able to use the Freedom of Information Act effectively, then we will begin to address and tackle corruption". FOIA enables the citizens to call Public servants to account and ask what it is they are doing in the conduct of government business.

\section{FOI Act, Democracy and Good Governance}

The Nigerian Freedom of Information (FOI) Act 2011 gives any person the right to ask any public institution for any record, data or information that is held in the institution's custody. Anyone can ask for information regardless of age, gender, disability, citizenship or geographical location. The law gives a legal footing to demand for information from such government bodies except on information that is exempted in the law (Ojo, 2015).

The FOI Act gives citizens legal guarantee to access public information, helps in strengthening democracy, since governments would become directly accountable to the governed. Effective implementation of the FOI law is therefore the greatest test of Nigeria's democracy or civilian rule. If well implemented, it will facilitate open government at the federal, states and Local Governments, because it makes more government information to be in public domain. No doubt, access to information is one essential pillar and a strategy towards improving governance, reducing corruption and strengthening democracy through enhanced participation and sustainable development.

Since its passage into law, the FOIA has become a major focus of media practitioners and other rights activists in Nigeria. It is a widely held belief that FOIA makes both government and private institutions serving public functions accountable. This is perhaps because freedom of information is the corner stone in promoting 
democratic participation and good governance. Reason being that an independent media has the capacity to not only scrutinize government but also hold it accountable. This is based on the premise that good journalism leads to good government policies and programmes. But for the policies and programmes to be good, people must be engaged to contribute in making them. Moreover, for people to do this, they must have access to information and ideas in an open and free environment. It is also indicative that for a democracy to answer its name, it must embrace the spirit of free press in principle and practice. After all, democratic governance is not about provision of infrastructure or amenities alone but respect and promotion of people's rights and freedoms. Moreover, worst tyrants who have been able to provide better critical infrastructural needs of their people could not save themselves from the wraths of the people because of the regimes' poor human rights records. The prevailing awakenings in parts of the world are a pointer in that direction.

Owuamalam (2015a) argue that the Freedom of Information Act promotes proactive explanation instead of reactive rebuttals. He identified prospects of the FOI in MDAs to include: a better understanding of government; an enhanced appreciation of role performance; a justification for excellence in public administration and a transparent and accountable government.

\section{Relevance of the FOI Act}

The denial of access to information and the attendant widespread ignorance in the Nigeria society has done more harm to the society than any harm that could possibly arise from granting access to members of the public (Ononammadu, 2015). As a country that witnessed decades of military rule during which press freedom was restricted and the colonial Official Secret Act fully applied, the FOI Act became a relief that could not come in a better time when culture of secrecy about all government information became entrenched. This was an era when every information not let out by government was classified as top secret and this veil of secrecy made it difficult to obtain information from any public/government institution because government information is tagged "classified", "confidential", "restricted", "not to be disclosed", "official secret".

The FOI Act provides citizens, students, researchers and politicians, easy access to information to conduct studies to understand how government processes, policies, systems and functions of public officers and offices work. It has legally prevented public servants from hiding under the plethora of known and unknown laws that prevent them from divulging official facts and figures to the public. Notable is the Official Secrets Act, which makes it an offence, not only for public servants to give out government information, but also for anyone to receive or reproduce such information, as well as other laws in the statute books that inhibit freedom of expression and freedom of speech.

Enonche (2012) argued that the FOI Act gives Nigerians the vital tool to hold public institutions accountable. No doubt, the Act is a vital tool to ensure democracy and responsible governance in Nigeria.

\section{Exemptions to the ACT}

There are certain categories of information that are exempted from the general right of access. They include:

- Defense/security matters;

- The conduct of international affairs;

- Law enforcement investigation;

- Trade secrets, financial, commercial, technical and scientific information of economic value; 
- Third party information, Solicitor/client privilege;

- Test questions and exam, etc.

\section{Applicability of the FOI Act}

The FOI Act gives members of the public a right of access to all government-held records \& information. This is however subject to the earlier listed exemptions. It can therefore be used to focus attention on any sector, institution, official or issue in which one has an interest.

- Information belonging to or about private entities are frequently held by government or government agencies \& therefore subject to the FOI Act. This is particularly so with regulatory agencies which oversee the activities of private entities and/or other government bodies.

- It is also applicable where private entities are required to submit periodic reports, audit reports, etc. to government agencies.

- The Act is also applicable where private entities have to apply to government agencies for licenses, permits, etc. or to renew them.

- Private entities also often hold discussions, consultations, negotiations, etc. with government agencies \& information from these are then documented $\&$ held by the agencies. They can be asked for.

\section{FOI Act and Nigeria's Anti-corruption War}

Transparency is a great disincentive against corruption and other unethical practices. FOI law is a great instrument for the fight against corruption in Nigeria. A strengthened FOI regime will enhance citizens' demand for accountability and prevent/check corruption in Nigeria.

Increased citizens' demand for accountability will naturally instill fear in public office holders and therefore check their excesses. Nigerians must take advantage of the Act to commence the journey towards the cleansing of the land. Corruption is pervasive in our society and exists at every level of the society. FOI law is one of the surest ways of holding public institutions accountable.

\section{Conclusion}

Some identified gaps notwithstanding: The FOI Act is a veritable tool for Nigeria's anti-corruption war. Every Nigerian must take advantage of the law to demand for accountability and transparency from public institutions. The awareness by government officials that their actions will be subjected to scrutiny and that any act of corruption or misconduct will ultimately be revealed will likely put pressure on them to act properly.

Nigerians must do away with docility and rise to the challenge of nation-building, through the entrenchment of an open society, where transparency and accountability is a culture. They must therefore begin to ask relevant questions and hold public institutions accountable. The FOI Act is a ready tool and we must take advantage of the law.

\section{Recommendations}

(1) Ministries, Departments and Agencies (MDAs) of government must partner in the implementation of the Act.

(2) Media and Civil Society organisations must take advantage of the FOI Act to entrench transparency and accountability in public institutions. 
(3) There is need for quarterly review meeting of stakeholders on the implementation of the FOI.

(4) An FOI use/implementation reward/award system should be introduced, to encourage competition.

(5) There is the need for sustained capacity building of citizens on the FOI Act, with a view to getting the masses to own the law, in order to effectively hold their leaders accountable.

\section{References}

Anokam, S. (2015). Freedom of Information Act and Bureaucratic processes in Nigeria. Proceedings from 2015 Roundtable on MDAs Compliance with the FOI Act in Nigeria. Abuja, Nigeria.

Anyakwe, N. (1994). Human rights education techniques in schools: Building attitudes and skills. Port Harcourt: Outreach Publications Press.

Duru, C. W. (2015a). Freedom of Information Act and the burden of obscurity in Nigeria. Proceedings from 2015 Roundtable on MDAs Compliance with the FOI Act in Nigeria. Abuja, Nigeria.

Duru, C. W. (2015b). Freedom of Information Act and the challenge of the practice of Journalism in Nigeria. Proceedings from the North Central/North East zonal Roundtable on Increased Use of the FOI Act. Abuja, Nigeria.

Duru, C. W. (2015c). The Role of the FOI Act in Nigeria's Anti-Graft War. Proceedings from a Roundtable meeting organised by J4A (DFID)/MIIVOC for CSO's and the Media in South-South Nigeria on increased use of the FOI Act in Nigeria.

Ojo, O. (2015). Combating corruption through the FOI Act. Proceedings a Media/Civil Society Roundtable on Nigeria's anti-corruption situation. Lagos.

Ononammadu, E. (2015). Nigeria's FOI Act: Opportunities and challenges. Proceedings from A Roundtable Meeting organised by J4A (DFID)/MIIVOC for CSO's and the Media in South-South Nigeria on increased use of the FOI Act in Nigeria.

Owuamalam, E. (2015a). Mainstreaming FOI into Extant Developmental Policies in Nigeria: Issues and Prospects. Proceedings from the 2015 Roundtable on MDAs Compliance with the FOI Act in Nigeria. Denis Hotel, Abuja, Nigeria.

Owuamalam, E. (2015b). A Critical Analysis of the FOI Act in Nigeria and Strategies for Engaging Public Institutions. Proceedings from the South-East zonal Roundtable for Civil Society Organisations on improved use of the FOI Act. Roban Hotel, Enugu.

Popper, K. R. (1995). The open society and its enemies. London: Routledge.

Wilson, D. (2015a). Donor Role in Freedom of Information Implementation in Nigeria. Proceedings from the 2015 Roundtable on MDAs Compliance with the FOI Act in Nigeria. Denis Hotel, Abuja, Nigeria.

Wilson, D. (2015b). FOI Act and the Role of Civil Society in Entrenching an Open Society in Nigeria. Proceedings from the South-South Roundtable on Freedom of Information Act. Roban Hotels Limited. 